\title{
Aplicações do Treinamento em Habilidades Sociais: Análise da Produção Nacional
}

\author{
Sheila Giardini Murta ${ }^{1}$ \\ Universidade Católica de Goiás
}

\begin{abstract}
Resumo
Habilidades sociais são reconhecidas como fator de proteção no curso do desenvolvimento humano. Por conseqüência, programas para o desenvolvimento de habilidades sociais têm sido desenvolvidos para promover saúde mental. Este artigo descreve programas de treinamento em habilidades sociais com amostras brasileiras para prevenção primária, secundária e terciária. Foram enfocados os participantes, delineamento, instrumentos de avaliação, técnicas de intervenção e resultados. A consulta a periódicos, base de dados LILACS e livros produzidos por grupos de pesquisa identificou 17 programas de intervenção. A literatura evidenciou o predomínio de programas em grupo, nos contextos clínico e escolar, com delineamentos pré-experimentais e uso de técnicas cognitivo-comportamentais. Os resultados encontrados foram promissores rumo a melhorias no desempenho social. São apresentadas sugestões para o planejamento de futuras intervenções.

Palavras-chave: Habilidades sociais; prevenção; avaliação; treinamento; intervenção.
\end{abstract}

\section{Applications of Training in Social Skills: Analysis of National Production}

\begin{abstract}
Social skills are recognized as protection factor in the human development course. As a result, programs targeted at development of social skills have been done to promote mental health. This article describes programs of social skills training with Brazilian samples for primary, secondary and tertiary prevention. Participants, design, evaluation instruments, intervention techniques and results were focused. Search on journals, LILACS base data and books written by research groups identified 17 intervention programs. The literature showed the predominance of programs in group, in clinical and educational contexts, with pre-experimental designs, and use of cognitive-behavioral techniques. Results found are promising toward improvement in social performance. Suggestions to planning of future interventions are presented.

Keywords: Social skills; prevention; evaluation; training; intervention.
\end{abstract}

Nas últimas décadas, um corpo consistente de conhecimentos vem sendo produzido em psicologia do desenvolvimento, psicopatologia e psicologia clínica acerca das relações entre habilidades sociais, desenvolvimento sócio-emocional e saúde (Arón \& Milicic, 1994; Cox \& Schopler, 1995; Del Prette \& Del Prette, 1996, 2003a; Lemos \& Meneses, 2002; Marinho, 2003). Tais habilidades dizem respeito a comportamentos necessários a uma relação interpessoal bem-sucedida, conforme parâmetros típicos de cada contexto e cultura, podendo incluir os comportamentos de iniciar, manter e finalizar conversas; pedir ajuda; fazer e responder a perguntas; fazer e recusar pedidos; defender-se; expressar sentimentos, agrado e desagrado; pedir mudança no comportamento do outro; lidar com críticas e elogios; admitir erro e pedir desculpas e escutar empaticamente, dentre outros (Caballo, 2003; Falcone, 2002). Além do conteúdo da fala, são igualmente relevantes na determinação da habilidade social outros aspectos concomitantes ao falar, do tipo não verbais (Ex.: postura e contato visual), cognitivo-afetivos (Ex.: auto-eficácia e leitura do ambiente), fisiológicos (Ex.: respiração e taxa cardíaca) e aparência pessoal e atratividade física (Del Prette \& Del Prette, 1999).

Embora a construção de um repertório socialmente habilidoso possa ocorrer em interações em contextos naturais sem treinamento formal, como no relacionamento entre pais e filhos, irmãos, colegas de escola, amigos e cônjuges (Gomide, 2003; Pacheco, Teixeira \& Gomes, 1999), comumente falhas ocorrem neste processo de aprendizagem, ocasionando déficits relevantes em habilidades

${ }^{1}$ Endereço para correspondência: Universidade Católica de Goiás, Departamento de Psicologia, Av. Universitária, no 1069, Setor Universitário, 74605 010, Goiânia, GO, Caixa Postal 086.E-mail:murta@cultura.com.br sociais. Há evidências crescentes de que déficits nestas habilidades estão correlacionados com fraco desempenho acadêmico, delinqüência, abuso de drogas, crises conjugais e desordens emocionais variadas, como transtornos de ansiedade (Del Prette \& Del Prette, 2001a, 2002a, 2003b; Marlatt, 1993).

A identificação de habilidades sociais como um fator de proteção no curso do desenvolvimento humano (Cecconello \& Koller, 2000) tem estimulado intervenções para a aprendizagem destas habilidades entre grupos e contextos distintos, com populações clínicas e não clínicas. De acordo com os objetivos gerais, tais intervenções podem ser agrupadas em prevenção primária, prevenção secundária e prevenção terciária. Intervenções em prevenção primária são dirigidas a grupos ou pessoas expostas a fatores de risco, mas ainda não acometidos por problemas interpessoais e visam ao incremento de suas habilidades sociais, como um fator de proteção, de modo a minimizar a chance de ocorrência de problemas interpessoais futuros para estas pessoas e para os que fazem parte de sua rede social mais próxima. Intervenções em prevenção secundária são voltadas para grupos ou pessoas já sob efeito de fatores de risco para problemas interpessoais, tais como crianças agressivas criadas por pais com problemas em práticas educativas parentais. As intervenções focadas em prevenção terciária almejam minimizar conseqüências de déficits acentuados em habilidades sociais já instalados, sem pretensão de cura, como é o caso de pessoas portadoras de autismo ou esquizofrenia. Considera-se, portanto, que programas de desenvolvimento de habilidades sociais sejam uma ferramenta valiosa em todos os níveis de atuação em saúde (Jeffery, 1989), sendo útil para minimizar fatores de risco e incrementar fatores de proteção ao desenvolvimento 
humano, tratar problemas já instalados passíveis de remissão e reduzir o impacto de déficits graves em habilidades sociais em pessoas portadoras de condições crônicas.

Este artigo tem por objetivo descrever a aplicabilidade do treinamento em habilidades sociais em intervenções psicológicas com amostras brasileiras, classificando-os de acordo com os três níveis de atuação em saúde: prevenção primária, prevenção secundária e prevenção terciária. Não se fará uma revisão exaustiva e sistemática da literatura, o que se pretende é oferecer ao leitor uma revisão narrativa da área de modo a indicar a abrangência e limites do treinamento em habilidades sociais em intervenções psicológicas nacionais, após breve caracterização do campo.

\section{Caracterização do Treinamento em Habilidades Sociais (THS)}

OTHS teve início na Inglaterra nos anos 1970 a partir dos estudos e publicações de Argyle, da Universidade de Oxford. Recebeu também contribuições da área de Treinamento Assertivo, em andamento na mesma época nos Estados Unidos e impulsionado por publicações de Wolpe (Del Prette \& Del Prette, 2000). Do ponto de vista da técnica, compreende duas etapas, não necessariamente separadas: a de avaliação e a de intervenção. A avaliação visa à identificação de déficits e excessos comportamentais, seus antecedentes e conseqüentes, respostas emocionais concomitantes e crenças distorcidas que estejam contribuindo para a não emissão de comportamentos socialmente habilidosos (Del Prette \& Del Prette, 1999; Falcone, 2002). Genericamente, as técnicas de avaliação utilizadas incluem entrevistas (Caballo, 2003), inventários (Del Prette \& Del Prette, 2001b, 2002b), técnicas derivadas da sociometria (Gomes da Silva, 2001), auto-registros (Caballo, 2003; Del Prette \& Del Prette, 1999) e observação direta do comportamento em situação natural (Löhr, 2003) ou de desempenho de papéis (Bandeira \& Ireno, 2002). As fontes de informação podem incluir o próprio cliente e outros significantes, como pais (Baraldi \& Silvares, 2003), professores (Lemos \& Meneses, 2002) e pares (Casares \& Caballo, 2000; Del Prette \& Del Prette, 2003b).

Não obstante os programas de treinamento em habilidades sociais tenham afiliações teóricas variadas, como teorias humanistas, sistêmicas, cognitivistas e comportamentalistas (Arón \& Milicic, 1994), parece predominar o uso de técnicas cognitivo-comportamentais em intervenções na área (Caballo, 2003; Del Prette \& Del Prette, 1999). As técnicas comumente empregadas podem compreender o fornecimento de instruções, ensaio comportamental, modelação, modelagem, feedback verbal e em vídeo, tarefas de casa, reestruturação cognitiva, solução de problemas, relaxamento (Caballo, 2003; Del Prette \& Del Prette, 1999) e, em caso de intervenções grupais, vivências (Del Prette \& Del Prette, 2001c, 2001d). Em seu conjunto, estas técnicas visam a modificar componentes comportamentais (como o ensaio comportamental), cognitivos (como a reestruturação cognitiva) e fisiológicos (como o relaxamento) típicos dos déficits em habilidades sociais.

A literatura apresenta duas formas de aplicação das intervenções para o desenvolvimento de habilidades sociais: multicomponentes e unicomponentes. Intervenções multicomponentes possuem múltiplos objetivos e diversos temas para discussão, dentre os quais se incluem habilidades de comunicação. Este é o caso de psicoterapia de casais (Cordova \& Jacobson, 1999), tratamentos grupais para depressão (Hermolin, Rangé \& Porto, 2000), intervenções junto a pessoas com fobia social (Markway, Carmin, Pollard \& Flynn, 1999), pânico e agorafobia (Rangé, 2001), prevenção de violência doméstica (Haase, Käppler \& Schaefer, 2000), manejo de dor crônica (Murta, 1999), manejo de estresse (Lipp, 1996), prevenção de recaída entre ex-alcoolistas (Marlatt, 1993) e programa de inserção ocupacional para jovens desempregados (Sarriera, Câmara \& Berlim, 2000), dentre outros. Tipicamente, estas intervenções incluem o treino de habilidades como assertividade, empatia e manejo de raiva, além de outros focos de mudança requeridos por cada contexto e população. Intervenções unicomponentes diferem das multicomponentes por serem focadas apenas em habilidades sociais (ou outro tema) e consistirão no objeto prioritário de análise neste artigo.

Um levantamento bibliográfico na base eletrônica de dados PsycINFO identificou 342 trabalhos com as palavras-chave "habilidades sociais e intervenção", em fontes de língua inglesa e espanhola, entre os anos de 1967 a 2003. Este volume de publicações evidencia um uso extenso do THS em outros países, aplicado a demandas notadamente variadas, incluindo autismo, abuso de drogas, violência, esquizofrenia, prevenção ao uso de tabaco, crianças com atraso de linguagem, déficit de atenção e hiperatividade, transtornos de ansiedade, dentre outros. Uma análise de publicações com as palavras-chave "habilidades sociais e intervenção" oriundas de a) resumos na base de dados LILACS; b) periódicos brasileiros indexados; c) anais de encontros da Associação Brasileira de Psicoterapia e Medicina Comportamental; e, d) livros produzidos por grupos nacionais de pesquisa sobre relações interpessoais revela que a produção brasileira teve início em meados da década de 1990. Algumas intervenções anteriores a esta época apareceram sob a denominação derivada da área da Assertividade (Del Prette, 1978) e do Treinamento Comportamental (Del Prette, 1985). A produção em THS vem crescendo nos últimos anos, mas permanece pequena se comparada à produção de países de língua inglesa e mesmo espanhola. Foram encontrados 17 programas de intervenção, aplicados predominantemente em formato grupal nos contextos escolar e clínico. A seguir estes programas serão descritos, de acordo com o foco em prevenção primária, secundária e terciária. Em cada trabalho, são descritas as populações alvo, instrumentos de avaliação, procedimentos para intervenção e principais resultados.

\section{Prevenção Primária}

Os trabalhos deste tipo identificados em nosso meio têm sido feitos com crianças de educação infantil e seus pais (Löhr, 2003), professores de rede pública de ensino (Del Prette, Del Prette, Torres \& Pontes, 1998), adolescentes e professores (Gorayeb, Cunha Netto \& Bugliani, 2003) e estudantes universitários (Falcone, 1999; Del Prette, Del Prette \& Barreto, 1999; Magalhães \& Murta, 2003).

Löhr (2003) conduziu uma intervenção dirigida a crianças entre 4 e 6 anos provenientes de pré-escolas públicas $(N=43)$ e seus pais. A 
intervenção consistiu em 10 encontros grupais, com 90 minutos de duração e intervalos semanais. Cada grupo continha em média 6 crianças. Tanto para as crianças quanto para os pais, os temas abordados foram assertividade, solução de problemas, leitura do contexto e empatia. Porém, no grupo de crianças, foram feitas atividades lúdicas, enquanto o grupo de pais recebeu instruções acerca de como prover condições antecedentes e reforçadoras de comportamentos socialmente habilidosos em seus filhos. Orientações semelhantes àquelas fornecidas aos pais foram fornecidas para os professores das crianças participantes do programa, a cada 15 dias. Uma sessão individual para devolução dos resultados aos pais e encaminhamentos foi feita ao fim da intervenção. Os resultados foram avaliados através de observação direta do comportamento das crianças, com uso de registro de evento e amostragem de tempo, feitas durante atividades escolares e durante a sessão terapêutica e de respostas dos pais ao Child Behavior Check-List de Achenbach (Achenbach, 1966, citado em Löhr, 2003), antes e após a intervenção. Os relatos dos pais evidenciaram progressos no repertório de habilidades sociais dos filhos, todavia não confirmados através dos dados observacionais obtidos durante as atividades escolares e sessões terapêuticas. Foram discutidas sugestões para aprimoramento dos procedimentos de avaliação e cuidados para maximizar a adesão ao programa. Em função das desistências ocorridas ao longo do programa, a autora advertiu que os resultados não podem ser generalizados, já que apenas pais altamente motivados permaneceram até o fim da intervenção.

Um programa visando promoção de habilidades sociais educativas em professores foi realizado por Del Prette e cols. (1998), denominado Programa de Desenvolvimento Interpessoal Profissional - PRODIP, implementado junto a 20 professores. A avaliação empírica do programa foi feita com uma amostra de seis professores de uma escola pública, que participaram de 12 sessões grupais de 90 minutos durante dois meses. Os temas foram discutidos em ordem crescente de dificuldade, avançado de habilidades sociais básicas, como dar e receber feedback e fazer perguntas, para habilidades sociais complexas, como coordenar e organizar grupos. As técnicas empregadas foram exercícios de aquecimento, discussão conceitual de temas relativos às habilidades sociais e aprendizagem, videofeedback, reforço diferencial e vivências grupais. Análises topográficas de dados coletados através de filmagens do desempenho em sala de aula, antes e após a intervenção, evidenciaram que todos os professores apresentaram progressos em algum componente não verbal, paralinguístico ou misto após a intervenção, bem como progressos em expressão facial, entonação, humor e entusiasmo. Além desta análise topográfica de aspectos moleculares das habilidades sociais, as filmagens foram também utilizadas para organizar uma tipologia de classes e subclasses do desempenho em sala de aula, descritas em Del Prette, Del Prette, Garcia, Bolsoni-Silva e Puntel (1998), que podem ser usadas em estudos futuros para avaliação da efetividade da intervenção e seu impacto no trabalho.
Del Prette e Del Prette (2003b) descreveram uma replicação do PRODIP em que filmagens do desempenho em sala de aula e videofeedback foram substituídos pelo ensino aos professores de vivências grupais voltadas para demandas emocionais, comportamentais e cognitivas; replicação da vivência com os alunos e discussão e análise desta experiência com feedbacks dos demais participantes e facilitadores do grupo. Em geral, os resultados desta nova versão apontaram para melhoria no repertório de habilidades sociais dos professores em suas relações no trabalho, bem como nas relações familiares e sociais.

Baseando-se em ações propostas pela Organização Mundial de Saúde (OMS), Gorayeb e colaboradores (2003) desenvolveram um programa denominado Habilidades de Vida junto a adolescentes e professores de uma comunidade de Ribeirão Preto (SP), com o objetivo de desenvolver habilidades para lidar com situações de risco que podem culminar em abuso de drogas, doenças sexualmente transmissíveis, gravidez precoce, violência no trânsito e morte por acidente. O programa foi constituído por 12 a 20 sessões grupais, de 90 minutos de duração, com encontros semanais, quando foram treinadas habilidades de tomada de decisão, resolução de problemas, pensamento crítico, pensamento criativo, comunicação eficaz, relacionamento interpessoal, autoconhecimento, empatia, lidar com as emoções e lidar com o estresse. Foram empregadas dinâmicas de grupo, exercícios de aquecimento, dramatizações, exposição oral e discussões. Avaliações não sistemáticas feitas através do relato verbal dos participantes evidenciaram melhora na interação grupal, melhora na interação dos participantes com o facilitador do grupo, melhora no estabelecimento de relações interpessoais fora do grupo e aumento de consciência sobre situações de risco e habilidades requeridas para seu manejo adequado.

Falcone (1999) conduziu uma intervenção junto a uma amostra não clínica composta por estudantes universitários a fim de desenvolver empatia. Tratou-se de um estudo experimental, em que 10 estudantes participaram de 11 sessões de 2 horas de duração, duas vezes na semana, enquanto sete estudantes participaram da condição controle. As técnicas usadas incluíram fornecimento de instruções, auto-observação para identificação de fatores dificultadores do comportamento empático, modelação encoberta, ensaio comportamental e prática das habilidades aprendidas em ambiente natural. Os participantes responderam a entrevistas antes da intervenção, foram filmados em situação de jogos de papéis ao início e fim da intervenção e 30 dias após a intervenção e responderam a um questionário para avaliar o impacto da intervenção nas relações cotidianas. Os resultados indicaram que os participantes do grupo experimental obtiveram melhora significativa na comunicação verbal no pós-treino e follow-up e em quatro dos aspectos da comunicação não-verbal (braços e pernas, posição da cabeça, proximidade e orientação), em comparação aos participantes do grupo controle.

Profissionais que utilizam muito das relações interpessoais em seu trabalho são particularmente exigidos a desenvolver habilidades sociais, sob pena de insucesso na profissão. Este é o caso de psicólogos e estudantes de psicologia. Uma intervenção dirigida a este grupo foi realizada por Del Prette, Del Prette e 
Barreto (1999), da qual participaram 39 alunos designados para o Grupo Experimental $(n=13)$ ou Grupo Controle $(n=23)$. A intervenção teve a duração de 40 horas, sendo as 20 primeiras dedicadas ao conteúdo teórico e as horas restantes dedicadas ao conteúdo vivencial. Foram realizadas sessões semanais de 90 minutos, para discussão de informações sobre promoção, avaliação e aplicabilidade do THS; e vivencias grupais para redução de ansiedade, reestruturação cognitiva, solução de problemas e desenvolvimento de habilidades sociais típicas de interações diádicas, grupais e profissionais, em grau de complexidade crescente. Os resultados foram avaliados através de respostas pré e pós-intervenção ao Inventário de Habilidades Sociais, respostas pós-intervenção a um questionário de avaliação de impacto do programa e observação direta de respostas comportamentais durante as sessões. Análise quantitativa dos dados evidenciou aumento significativo em habilidades sociais no grupo experimental em comparação ao grupo controle. Análises qualitativas revelaram satisfação dos participantes para com os efeitos do programa.

Magalhães e Murta (2003) desenvolveram um programa também dirigido a estudantes de psicologia. Sete acadêmicos de psicologia da Universidade Católica de Goiás participaram de sete sessões grupais, com 90 minutos cada e periodicidade semanal. Foram discutidos os temas práticas educativas parentais e sua relação com as habilidades sociais; diferenças entre assertividade, passividade e agressividade; direito assertivo e crenças irracionais; escuta empática; lidar com elogios e críticas; manejo de raiva e falar em público. Técnicas vivenciais, ensaio comportamental, modelagem, reestruturação cognitiva, relaxamento e exposição dialogada foram as principais técnicas utilizadas. Aplicou-se o Inventário de Habilidades Sociais de Del Prette e Del Prette - IHS (2001b) antes e após intervenção para avaliação dos resultados. Utilizou-se um Checklist de Habilidades Sociais, construído pelas autoras, para se observar a ocorrência de comportamentos socialmente habilidosos na interação entre membros do grupo durante as sessões, tais como elogiar, expressar afeto e discordar. O Checklist de Comportamentos Clinicamente Relevantes (Murta, 2005) foi também utilizado para se observar a ocorrência na sessão de comportamentos potencialmente favorecedores de mudança, tais como relatar problemas, explicar causas do próprio comportamento e fornecer apoio à colega. A avaliação dos resultados indicou que, após a intervenção, seis participantes apresentaram aumento no escore total de habilidades sociais e que a média grupal aumentou nos cinco escores fatoriais do IHS-Del-Prette. A avaliação de processo evidenciou ocorrência de habilidades sociais e comportamentos clinicamente relevantes na interação grupal ao longo das sessões, indicando coerência entre o processo e os resultados finais obtidos.

\section{Prevenção Secundária}

Boa parte das intervenções para prevenção secundária com amostras brasileiras, descrita na literatura, tem sido feita em clínicas escolas de Psicologia e em escolas de ensino fundamental. Crianças, adolescentes, pais e adultos com problemas de relacionamento interpessoal constituem a clientela usual. Considerando que a maioria das pessoas que buscam atendimento psicológico apresentam problemas nas interações pessoais e respostas emocionais associadas, Vila, Silveira e Gongora (2003) realizaram uma intervenção com adultos com padrões de comportamento passivo e hostil que estavam em lista de espera em uma clínica escola da Universidade Estadual de Londrina. A intervenção consistiu em três etapas: 4 sessões individuais de preparação para a inserção no grupo; 12 sessões grupais de análise funcional e treino em habilidades sociais e followup, com 4 atendimentos quinzenais e 2 telefonemas semestrais para verificação da manutenção das mudanças. A primeira fase foi conduzida a fim de prevenir desistências através da preparação do cliente para enfrentar situações sociais potencialmente desafiadoras em grupo. Tarefas de casa, modelagem e aplicação de inventários para avaliação de déficits em habilidades sociais foram feitas neste primeiro momento. A segunda fase foi feita com o uso de exercícios de: aquecimento; direitos humanos básicos; discriminação das diferenças entre assertividade, agressividade e passividade; iniciar e manter conversações; defesa e ataque; tarefas de casa e análise funcional. Ao final desta etapa, foram reaplicados os inventários já respondidos antes da intervenção grupal. A terceira fase, de follow-up, foi feita para se prevenir recaídas e se, necessário, encaminhar o cliente para outras formas de atendimento psicológico. Embora não tenham sido analisados sistematicamente os resultados desta intervenção, os relatos dos participantes permitiram às autoras argumentar favoravelmente à eficácia da intervenção: aumento de assertividade e empatia e discriminação das causas das próprias dificuldades interpessoais foram alguns dos resultados apresentados pelas autoras. Elas consideraram que foram aspectos positivos neste programa a heterogeneidade na composição dos grupos quanto ao repertório de habilidades sociais e o período inicial de preparação para o trabalho grupal. As autoras sugeriram que o efeito deste último aspecto seja avaliado empiricamente em estudos futuros.

Há evidências consistentes de que o comportamento anti-social na adolescência e idade adulta tem como preditores práticas educativas parentais deficitárias quanto à disciplina e ao monitoramento, fracasso acadêmico e rejeição entre pares (Gomes da Silva, 2001; Silveira, Silvares \& Marton, 2003). Estes achados têm encorajado o desenvolvimento de programas interventivos junto a crianças em idade escolar para diagnóstico precoce e prevenção secundária de rejeição entre pares. Tais programas visam a identificar crianças percebidas pelo grupo de colegas como rejeitadas ou impopulares e promover o desenvolvimento de comportamentos pró-sociais como oferecer ajuda, fazer e receber elogios, estabelecer contato visual, defender os próprios interesses, desculpar-se, expressar raiva e frustração de modo aceitável, dentre outros, através do uso de estratégias lúdicas (Gomes da Silva, 2001).

Levantamentos acerca de características da clientela de clínicas-escola de Psicologia brasileiras identificaram que a agressividade infantil é uma das três queixas mais freqüentes entre a população infantil (Silvares, 2000), indicando ser esta uma das principais demandas para prevenção de rejeição entre pares. Em 
adição a isto, a literatura é consistente ao apontar uma correlação positiva entre práticas educativas parentais caracterizadas por autoritarismo e problemas de comportamento externalizantes (Bolsoni-Silva \& Marturano 2002; Gomide, 2003; Lubi, 2003; Marinho, 2003; Oliveira \& cols., 2002). Tais constatações têm embasado a proposta de intervenções para pais e crianças com condutas anti-sociais a fim de incrementar fatores de proteção (Ex.: habilidades sociais parentais) e enfraquecer fatores de risco (Ex.: hostilidade e crítica por parte dos pais) (Silveira \& cols., 2003). Silvares $(2000,2001)$ desenvolveu uma intervenção para crianças agressivas, recrutadas em uma clínicas-escola, que consistia na associação de ludoterapia infantil e recreação em grupo enquanto os pais recebiam orientação também em grupo, num total de 15 sessões para cada grupo. Foram utilizadas as técnicas de leitura e contação de estórias, jogos lúdicos e discussão em grupo nas sessões de ludoterapia, brincadeiras variadas nas sessões de recreação e ensino de estratégias de manejo comportamental (Ex.: registro de comportamentos, atenção diferencial, extinção, resolução de problemas, modelação e fornecimento de instruções) nas sessões de orientação aos pais. Foram feitas avaliações antes e após a intervenção, com observação direta do comportamento da criança em consultório (registros em vídeo) e em casa (registros em fitas de áudio), relatos dos pais acerca de como percebiam o comportamento dos filhos através do Child Behavior Checklist de Achenbach (Achenbach, 1966, citado em Silvares, 2001) e avaliação pelos pares da condição de rejeição ou aceitação da criança. Os resultados evidenciaram aumento na competência social no que se refere às classes comportamentais de perceber e dar dicas para a entrada em grupos, perguntar e responder a perguntas, cumprimentar amigos, participar de tarefas e seguir instruções, cooperar e elogiar colegas; alteração positiva das percepções dos pais sobre o comportamento dos filhos e redução de interações negativas e aumento de interações positivas entre pais e filhos.

Uma intervenção almejando aumentar habilidades de solução de problemas interpessoais em crianças de ensino fundamental foi implementada e avaliada por Borges e Marturano (2003). Participaram 55 crianças provenientes da $1^{\text {a }}$ série, designadas para a condição intervenção $(n=31)$ e condição comparação $(n=24)$. A intervenção foi adaptada do programa "Eu posso resolver problemas", de Shure (1992, citado em Borges \& Marturano, 2003) e consistia no ensino de habilidades tais como negociar relacionamentos, lidar com as frustrações, habilidades cognitivas de solução de problemas e a incorporação de tais habilidades nas interações cotidianas em sala de aula. Foram realizadas entre duas a três sessões por semana, durando 15 a 20 minutos cada, ao longo de 6 meses. A condição comparação não recebeu qualquer intervenção. Antes e após a intervenção, foi feita observação direta do comportamento das crianças das duas condições em situação de desempenho de papéis sobre solução de problemas. Adicionalmente, as crianças da condição intervenção tiveram seu comportamento de lidar com problemas interpessoais observado ao longo da intervenção e registrado em um diário de campo. Análises estatísticas por meio de ANCOVA indicaram índices de habilidades de solução de problemas interpessoais superiores entre as crianças da condição intervenção em comparação às crianças da condição controle. Testes $t$ entre as médias pré e pós-intervenção em cada grupo indicaram progressos nos índices de habilidades de solução de problemas interpessoais para o grupo intervenção mas não para o grupo controle. As observações feitas ao longo do programa evidenciaram que os alunos que inicialmente se envolviam mais em conflitos diminuíram sua participação nesses eventos durante a intervenção.

Outra intervenção aplicada em contexto escolar foi conduzida por Molina e Del Prette (2002). Participaram 16 estudantes com dificuldades na aprendizagem da leitura e escrita distribuídos em três condições experimentais: Grupo Habilidades Sociais, Grupo de Ensino de Leitura e Grupo Controle, sem intervenção. O primeiro grupo recebeu 40 sessões de 90 minutos focadas no desenvolvimento de habilidades sociais. Foram usados procedimentos lúdicopedagógicos, modelação, instrução, solução de problemas, feedback, role-playing, reforçamento e procedimentos para generalização dos ganhos. O segundo grupo recebeu 70 sessões de 60 minutos destinadas ao ensino de palavras de duas e três sílabas, de acordo com o método de controle de estímulo. Antes e após a intervenção, os participantes responderam ao Inventário Multimídia de Habilidades Sociais para Crianças (Del Prette \& Del Prette, s.d.), os professores responderam ao Protocolo de Avaliação da Competência Social Junto ao Professor (Del Prette \& Del Prette, 2003b) e todos os alunos da classe responderam ao sociograma. O repertório acadêmico de todos os participantes foi avaliado pré e pósintervenção por meio da observação e registro de respostas em atividades de leitura, nomeação e ditado. Os resultados evidenciaram ganhos pós-intervenção em habilidades sociais e acadêmicas nos participantes do Grupo Habilidades Sociais e apenas ganhos acadêmicos nos participantes do Grupo de Ensino e Leitura.

Diferentemente das intervenções anteriores dirigidas a crianças ou adultos, Amaral, Bravo e Messias (1996) conduziram uma intervenção junto a adolescentes com idades entre 12 e 16 anos. Participaram 5 adolescentes com deformidade facial, recrutados em um instituto de cirurgia plástica, com dificuldades em habilidades sociais resultantes da condição física que comprometia a atratividade física. Foram realizadas oito sessões em grupo de 90 minutos cada, para treino de habilidades tais como conversar com os colegas, exporse perante os outros, fazer pedidos, participar de atividades grupais, pedir ajuda e fazer convites. As técnicas usadas foram vivências, fornecimento de instruções e tarefas de casa. Os resultados foram avaliados através da aplicação do Inventário de Habilidades Sociais de Adolescentes antes e após a intervenção e da análise funcional da filmagem das sessões. Ao fim da intervenção, foram identificados progressos em solicitar ajuda a professores, defender os próprios direitos e conversar com pessoas do sexo oposto. A análise funcional das sessões revelou que a frequência de iniciar conversação cresceu durante as sessões e que o grupo atuou como fonte de suporte social quando problemas interpessoais foram relatados.

Outra intervenção dirigida a adolescentes foi feita por Conte (1996), que conduziu um programa de apoio ao desenvolvimento global e prevenção de delinqüência junto a 47 crianças e adolescentes com comportamentos delinqüentes. Os participantes foram designados para três condições experimentais: grupo terapêutico, 
lista de espera e validação social. Os participantes do grupo terapêutico foram submetidos a 30 sessões, quando foram utilizadas técnicas derivadas da Análise do Comportamento para o desenvolvimento de autoconhecimento e habilidades pró-sociais. Os participantes das três condições responderam, antes e após a intervenção, a uma entrevista com aplicação do Inventário Youth SelfReport de Achenbach e receberam notas das instrutoras sobre seu comportamento. Os resultados evidenciaram que os participantes do grupo terapêutico apresentaram uma redução na pontuação referente aos distúrbios internalizantes e à síndrome do Comportamento Delinqüente, enquanto estes indicadores permaneceram inalterados nas demais condições. A autora concluiu afirmando que a intervenção promoveu ganhos positivos, não observados entre os participantes não expostos à intervenção.

\section{Prevenção Terciária}

As intervenções encontradas na literatura nacional com foco em prevenção terciária foram realizadas junto a pessoas com gagueira (Gomes \& Scrochio, 2001), pais de crianças com deficiência mental e/ou autismo (Grossi, 2003), crianças com deficiência mental leve (Paula, 1999), síndrome de Asperger (Fernandes \& Souza, 2000) e esquizofrenia (Araújo \& Del Prette, 2003).

A gagueira é caracterizada por alterações em componentes comportamentais verbais de forma da fala, como fluência, ritmo e latência, em componentes cognitivo-afetivos, como autoeficácia e autoconceito e em componentes fisiológicos, como respiração irregular. Isto resulta em fala disfluente, expressões faciais inadequadas concomitantes à fala, como piscar olhos e franzir testa, pouca atratividade física e ansiedade nas relações interpessoais (Gomes \& Scrochio, 2001). Estes autores realizaram um programa integrado de atuação fonoaudiológica e psicológica para tratamento da gagueira. Três pessoas com gagueira participaram de 22 sessões focadas no fornecimento de informações sobre a gagueira, na adequação dos componentes comportamentais de forma da fala, como fluência, ritmo e latência, e na redução de componentes afetivo-cognitivos indesejáveis associados à fala, como baixa autoconfiança e sentimentos de vergonha e ansiedade. Exercícios para treino da velocidade da fala, melodia, entonação e suavidade da emissão foram parte da atuação fonoaudiológica e análise funcional do comportamento de gaguejar, treino respiratório e relaxamento, treino em atividades incompatíveis com o gaguejar e dessensibilização sistemática foram parte da atuação psicológica. Filmagens dos participantes em situação de fala espontânea e fala dirigida foram feitas ao início e fim da intervenção e analisadas conforme protocolos do Stuttering Severity Instrument for Children and Adults. Embora não tenha ocorrido a extinção da gagueira ao fim da intervenção, os resultados indicaram diminuição em disfluências na fala espontânea, aumento do repertório de enfrentamento a situações sociais com diminuição de fuga e esquiva de contatos interpessoais, diminuição de concomitantes físicos (Ex.: movimentos com a cabeça, respiração ruidosa e estalo de língua) e diminuição na intensidade de sentimentos de medo e vergonha. Implicações para melhoria da qualidade de vida dos participantes e para aprimoramento de intervenções grupais com esta população foram discutidas pelos autores.

Crianças com deficiência mental, autismo e outros transtornos do desenvolvimento constituem população alvo para prevenção terciária, haja vista ser comum neste grupo comprometimentos graves em habilidades sociais. Grossi (2003) propôs um programa de atendimento à família especial com base na Análise do Comportamento, destinado a diminuir comportamentos inadequados e aumentar comportamentos adequados na interação entre pais e filhos com deficiência mental e/ou autismo e outros agentes relevantes. O programa consiste em atendimentos domiciliares, com análise funcional e ensino de habilidades sociais e de manejo à família, incluindo reforçamento (Ex.: dar atenção e autonomia à criança, manter contato físico, conversar), postura (Ex.: uso de tom de voz, linguagem e expressão facial adequados), estabelecimento de limites e estratégias para favorecer a aprendizagem, dentre outras. Cuidados para adesão ao programa, generalização entre pessoas, contextos e manutenção de ganhos são previstos no procedimento. Análises preliminares dos efeitos do programa revelaram ganhos para os pais, como uso de habilidades aprendidas com os outros filhos e da análise funcional para prevenir problemas, e ganhos para os filhos, como estabelecimento de relações sociais como novas pessoas e ambientes e aumento em fontes de reforçamento, embora isto necessite ser averiguado sistematicamente. A autora propõe ainda que atendimentos paralelos aos domiciliares sejam integrados ao programa, como orientações grupais e palestras informativas para os pais ou psicoterapia, quando necessário.

Uma intervenção nesta área focada na criança foi conduzida por Fernandes e Souza (2000), que realizaram terapia comportamental com uma criança de 10 anos com síndrome de Asperger, que apresentava isolamento social e comportamento excêntrico. Ao longo do processo terapêutico foram feitos treinos de atenção e memória, reforço diferencial, modelação, treino de habilidades sociais verbais e não verbais e estratégias com desenhos. Observações assistemáticas dos resultados evidenciaram diminuição dos movimentos estereotipados e impulsividade, melhora na comunicação verbal, contato visual e físico e interação social. As autoras concluíram que este estudo de caso sugere efetividade da terapia comportamental no desenvolvimento de habilidades sociais e autocontrole.

Dados cumulativos acerca da correlação entre dificuldades de aprendizagem e habilidades sociais vêm sendo produzidos, o que sugere a necessidade de programas interventivos. Neste sentido, Paula (1999) desenvolveu e avaliou efeitos de um programa de desenvolvimento de habilidades sociais em 8 crianças portadoras de necessidades especiais, integrantes de uma classe especial em uma escola regular. Foram conduzidas 27 sessões, quando foram empregadas técnicas lúdicas e pedagógicas. A avaliação do programa foi feita através de comparações intra-sujeitos e comparações com crianças integrantes de um grupo controle. Antes e após a intervenção, foi aplicado um inventário em alunos e professores e foram filmadas 
situações de interação em sala de aula durante as sessões de intervenção. Análises de conteúdo, categorização dos dados observacionais e avaliação quantitativa do inventário evidenciaram que, ao fim da intervenção, algumas das crianças participantes do programa apresentaram progressos em comportamentos verbais e não-verbais, embora restritos à interação com a professora, e indícios de respostas socialmente habilidosas quanto à definição de sentimentos. Identificou-se contradição entre as respostas das professoras ao inventário e as auto-avaliações dos alunos e observação direta de seu desempenho. Conclui-se a favor da efetividade parcial do programa e salienta-se a necessidade do desenvolvimento de instrumentos de avaliação de habilidades sociais em crianças e de procedimentos para desenvolver a acurácia de professores na observação e avaliação do desempenho de alunos.

Com o movimento de desinstitucionalização psiquiátrica, pacientes psiquiátricos, particularmente aqueles com esquizofrenia, encontram dificuldades ao retornarem à comunidade em função de seus déficits em habilidades básicas para manejo de situações cotidianas e de habilidades sociais, sobretudo para lidar com conflitos interpessoais. Conforme Bandeira (2003), para facilitar a reinserção social desta população, são necessários, além da medicação, intervenções junto à família do paciente e o treino em habilidades sociais e instrumentais. Programas de acompanhamento intensivo na comunidade constituem uma das opções metodológicas para o ensino de tais habilidades. Araújo e Del Prette (2003) realizaram uma intervenção em acompanhamento terapêutico com duas mulheres com diagnóstico de psicose esquizofrênica residual que residiam em moradia extra-hospitalar vinculada a um serviço de saúde mental. Foram realizadas 24 sessões de acompanhamento com a dupla de mulheres, com um tempo médio de 3 horas de duração cada, com o objetivo de facilitar o desenvolvimento de suas habilidades instrumentais e sociais, tais como aprendizagem de cuidados com alimentação e saúde, higiene pessoal e estética; aprendizagem de locomoção na comunidade; uso de recursos da comunidade e desenvolvimento de pensamento crítico e aprendizagem de reivindicação e exercício de direitos. O conteúdo verbal das sessões foi gravado e submetido à análise de conteúdo. A análise destes dados permitiu a identificação de três classes de interações verbais entre a acompanhante e as acompanhadas: estratégias de instigação (Ex.: promover a cooperação), estratégias de orientação (Ex.: estabelecer limites) e estratégias de apoio (Ex.: fazer elogios). Verificou-se que este tipo de interação verbal atuou como elemento promotor de maior autonomia por parte das participantes do estudo, de modo a facilitar seu processo de reabilitação psicossocial.

\section{Conclusões}

Esta revisão identificou 17 publicações descritivas de THS com amostras brasileiras, distribuídas quase que igualmente entre prevenção primária (06), prevenção secundária (06) e prevenção terciária (05).
A maior parte delas utilizou instrumentos verbais para avaliação de resultados e técnicas observacionais para avaliação de processo (Posavac \& Carey, 2003). Em algumas das intervenções, foram conjugadas as fontes de informação para a coleta de dados como pais e crianças ou professores e crianças. Este panorama geral revela grande variabilidade em contextos de aplicação de treinamento em habilidades sociais e uma tendência de avaliação conforme o princípio da triangulação, isto é, de associar instrumentos e fontes de informação diferentes para verificação do mesmo objetivo. Tal tendência é bemvinda por favorecer o fornecimento de informações mais completas sobre a efetividade destas intervenções.

Grande parte dos programas descritos utilizou delineamento préexperimental com pré e pós-teste. Apenas seis estudos utilizaram delineamentos experimentais ou quase-experimentais com grupos controle (Borges \& Marturano, 2001; Conte, 1996; Del Prette, Del Prette \& Barreto, 1999; Falcone, 1999; Paula, 1999; Molina \& Del Prette, 2002). Isto dificulta a interpretação dos resultados e evidencia a necessidade de fortalecimento de cuidados para assegurar maior validade interna, seja com a inserção de grupos controle, grupos de comparação com tratamentos alternativos ou medidas repetidas intrasujeito antes e após a intervenção.

Contudo, os resultados desta revisão devem ser interpretados com cautela, dado que os estudos ora descritos foram apenas os publicados e podem refletir de modo enviesado a produção nacional em THS. E provável que diversos outros programas tenham sido conduzidos e não tenham sido publicados. Neste caso, o acesso a trabalhos não-publicados poderia resultar em um panorama diferente (ou não) da produção nacional. Outro limite desta revisão é seu caráter narrativo e os vieses decorrentes. À medida que as evidências empíricas se acumularem, é recomendável que revisões sistemáticas e metas-análises acerca da efetividade destes programas venham a ser conduzidas no futuro. Tais revisões poderão identificar que tipo de programa de THS é mais efetivo, para quem e em quais circunstâncias.

Conciliar as demandas de pesquisa rigorosa com intervenção bem sucedida no "mundo real" é uma tarefa desafiadora, porém necessária para o progresso da área. Neste sentido, algumas sugestões para o planejamento de intervenções futuras podem ser fornecidas, incluindo a aspectos relativos a avaliação de efetividade dos programas em THS, a expansão de contextos de aplicação e a replicação de algumas intervenções. No primeiro aspecto, sugere-se que estudos futuros incluam a avaliação de resultados em longo prazo, especialmente os programas de prevenção primária, cujos resultados podem precisar de anos para se manifestar; o uso de delineamentos experimentais, quaseexperimentais ou longitudinais para maior controle de ameaças à validade interna e o uso de grupos de comparação com tratamentos alternativos às habilidades sociais, ao invés de grupos controle com tratamento nulo, como opção metodológica para atender às demandas éticas de pesquisas em contextos aplicados. No segundo aspecto, sugere-se a expansão das intervenções em prevenção primária para creches, programas de atendimento à comunidade e cursos de formação de profissionais de saúde em 
geral; a expansão das intervenções para prevenção secundária e terciária para hospitais, ambulatórios e outros contextos que lidam com condições tais hipertensão, estresse, controle de tabagismo e obesidade, as quais poderiam se beneficiar de intervenções multicomponentes para desenvolvimento de habilidades sociais e outras habilidades de autocuidados e promoção de qualidade de vida. No terceiro aspecto, sugere-se que as intervenções bem sucedidas em clínicas escolas sejam replicadas em clínicas escolas de outras regiões do país, para melhor cumprimento do papel social da universidade e consolidação desta área de pesquisa.

Em conclusão, a produção nacional em programas de treino em habilidades sociais, ainda que tenha tido início recente, tem sido implementada em grande parte por meio de delineamentos pré-experimentais em contextos diversificados e com cuidados metodológicos relevantes. Isto torna a produção atual uma contribuição valiosa para clínicos e pesquisadores interessados no desenvolvimento de tecnologia comportamental para promoção de saúde e desenvolvimento humano, estimulando o desdobramento de inúmeros estudos futuros em campos variados de aplicação.

\section{Referências}

Amaral, V. L. A. R., Bravo, M. C. M. \& Messias, T. S. C. (1996). Desenvolvimento de habilidades sociais em adolescentes portadores de deformidades faciais. Estudos de Psicologia (Campinas), 13, 31-47.

Araújo, A. \& Del Prette, A. (2003). Acompanhamento terapêutico e reabilitação psicossocial: Resultados de uma pesquisa-intervenção. Em Z. A. Trindade \& A. N. Andrade (Orgs.), Psicologia e saúde: Um campo em construção (pp. 101-127). São Paulo: Casa do Psicólogo.

Arón, A. M. \& Milicic, N. (1994). Viver com os outros: Programa de desenvolvimento de habilidades sociais (J. P. Santos, Trad.). Campinas, SP: Psy.

Bandeira, M. (2003). Avaliando a competência social de pacientes psiquiátricos: Questões conceituais e metodológicas. Em A. Del Prette \& Z. A. P. Del Prette (Orgs.), Habilidades sociais: Desenvolvimento e aprendiragem: Questões conceituais, avaliação e intervenção (pp. 207-234). Campinas, SP: Alínea.

Bandeira, M. \& Ireno, E. M. (2002). Reinserção social de psicóticos: Avaliação global do grau de assertividade, em situações de fazer e receber crítica. Psicologia: Reflexão e Crítica, 15, 665-675.

Baraldi, D. M. \& Silvares, E. F. M. (2003). Treino de habilidades sociais em grupo com crianças agressivas, associado à orientação dos pais: Análise empírica de uma proposta de atendimento. Em A. Del Prette \& Z. A. P. Del Prette (Orgs.), Habilidades sociais: desenvolvimento e aprendiragem: Questöes conceituais, avaliação e intervenção (pp. 235-259). Campinas, SP: Alínea.

Bolsoni-Silva, A. T. \& Marturano, E. M. (2002). Práticas educativas e problemas de comportamento: Uma análise à luz das habilidades sociais. Estudos de Psicologia (Natal), 7, 227-235.

Borges, D. S. C. \& Marturano, E. M. (2003). Desenvolvendo habilidades de solução de problemas interpessoais no ensino fundamental. Paidéia, 12, 185-193.

Caballo, V. E. (2003). Manual de avaliação e treinamento das habilidades sociais. São Paulo: Santos.

Casares, M. I. M. \& Caballo, V. E. (2000). A timidez infantil. Em E. F. M. Silvares (Org.), Estudos de caso em psicologia clínica comportamental infantil (Vol. 2; pp. 1142). Campinas, SP: Papirus.

Cecconello, A. M. \& Koller, S. H. (2000). Competência social e empatia: Um estudo sobre a resiliência com crianças em situação de pobreza. Estudos de Psicologia (Natal), 5, 71-93.

Conte, F. C. S. (1996). Pesquisa e intervenção clinica em comportamento delinqüente numa comunidade pobre. Tese de Doutorado não-publicada, Universidade de São Paulo. São Paulo, SP.
Cordova, J. V. \& Jacobson, N. S. (1999). Crise de casais (M. R. B. Osório, Trad.). Em D. H. Barlow (Org.), Manual clinico dos transtornos psicológicos (pp. 535-567). Porto Alegre: Artmed. (Original publicado em 1993)

Cox, R. D. \& Schopler, E. (1995). Treinamento de habilidades sociais para crianças (I. C. S. Ortiz, S. Costa \& D. Batista, Trads.). Em M. Lewis (Org.), Tratado de psiquiatria da infância e adolescência (pp. 916-923). Porto Alegre: ArtMed. (Original publicado em 1991)

Del Prette, A. (1978). O treino assertivo na formação do psicólogo. Arquivos Brasileiros de Psicologia Aplicada, 30, 53-55.

Del Prette, A. (1985). Treinamento Comportamental em grupo: Uma análise descritiva de procedimento. Psicologia, 11, 39-54.

Del Prette, A. \& Del Prette, Z. A. P. (2001d). Psicologia das relaçōes interpessoais: Vivencias para o trabalho em grupo. Petrópolis, RJ: Vozes.

Del Prette, A. \& Del Prette, Z. A. P. (2003a). Aprendizagem sócio-emocional na infância e prevenção da violência: Questões conceituais e metodologia da intervenção. Em A. Del Prette \& Z. A. P. Del Prette (Orgs.), Habilidades sociais, desenvolvimento e aprendizagem: Questões conceituais, avaliação e intervenção (pp. 83127). Campinas, SP: Alínea.

Del Prette, A., Del Prette, Z. A. P. \& Barreto, M. C. M. (1999). Habilidades sociales en la formación del psicólogo: Análisis de un programa de intervención. Psicología Conductual (Espanha), 7, 27-47.

Del Prette, A., Del Prette, Z. A. P., Torres, A. C. \& Pontes, A. C. (1998). Efeitos de uma intervenção sobre a topografia das habilidades sociais de professores. Psicologia Escolar e Educacional, 2, 11-22.

Del Prette, Z. A. P. \& Del Prette, A.(s/d). Inventário Multimídia de Habilidades Sociais para Crianças (IMHSC-Del-Prette): Manual do Examinador.

Del Prette, Z. A. P. \& Del Prette, A. (1996). Habilidades sociais: Uma área em desenvolvimento. Psicologia Reflexão e Crítica, 9, 233-255.

Del Prette, Z. A. P. \& Del Prette, A. (1999). Psicologia das habilidades sociais: Terapia e educação. Petrópolis, RJ: Vozes.

Del Prette, Z. A. P. \& Del Prette, A. (2000). Treinamento em habilidades sociais: Panorama geral da área. Em V. G. Haase, R. Rothe-Neves, C. Käppler, M. L. M. Teodoro \& G. M. O. Wood (Orgs.), Psicologia do desenvolvimento: Contribuições interdisciplinares (pp. 249-264). Belo Horizonte: Health.

Del Prette, Z. A. P. \& Del Prette, A. (2001a). Habilidades sociais e educação: Pesquisa e atuação em psicologia escolar/ educacional. Em Z. A. P. Del Prette (Org.), Psicologia escolar e educacional: Saúde e qualidade de vida (pp. 113-141). Campinas, SP: Alínea.

Del Prette, Z. A. P. \& Del Prette, A. (2001b). Inventário de habilidades sociais (IHS-DelPrette): Manual de apuração e interpretação. São Paulo: Casa do Psicólogo.

Del Prette, Z. A. P. \& Del Prette, A. (2001c). O uso de vivências no treinamento de habilidades sociais. Em M. L. Marinho \& V. E. Caballo (Org.), Psicologia clínica e da saúde (pp. 117-135). Granada (Espanha), Londrina (Brasil): Ed. UEL e APICSA.

Del Prette, Z. A. P. \& Del Prette, A. (2002a). Transtornos psicológicos e habilidades sociais. Em H. J. Guilhardi, M. B. B. P. Madi, P. P. Queiroz \& M. C. Scoz (Orgs.), Sobre comportamento e cognição. Contribuições para a construção da teoria do comportamento (pp. 377-386). Santo André, SP: ESETec.

Del Prette, Z. A. P. \& Del Prette, A. (2002b). Avaliação de habilidades sociais de crianças com um inventário multimídia: Indicadores sociométricos associados à frequência versus dificuldade. Psicologia em Estudo, 7, 61-73.

Del Prette, Z. A. P. \& Del Prette, A. (2003b). Habilidades sociais e dificuldades de aprendizagem: Teoria e pesquisa sob um enfoque multimodal. Em A. Del Prette e Z. A. P. Del Prette (Orgs.), Habilidades sociais, desenvolvimento e aprendizagem: Questões conceituais, avaliação e intervenção (pp. 167-206). Campinas, SP: Alínea.

Del Prette, Z. A. P., Del Prette, A., Garcia, F. A., Bolsoni-Silva, A. T. \& Puntel, L. P. (1998). Habilidades sociais do professor em sala de aula: Um estudo de caso. Psicologia: Reflexão e Crítica, 11, 591-603.

Falcone, E. (1999). Avaliação de um programa de treinamento da empatia com universitários. Revista Brasileira de Terapia Comportamental e Cognitiva, 1, 23-32.

Falcone, E. O. (2002). Contribuições para o treinamento de habilidades de interação. Em H. J. Guilhardi, M. B. B. P. Madi, P. P. Queiroz \& M. C. Scoz (Orgs.), Sobre comportamento e cognição. Contribuições para a construção da teoria do comportamento (pp. 91-104). Santo André, SP: ESETec.

Fernandes, P. T. \& Souza, E. A. P. (2000). Terapia comportamental na síndrome de asperger: Um estudo exploratório. Temas em Desenvolvimento, 9, 19-23. 
Gomes da Silva, V. R. M. (2001). Reconhecendo e prevenindo a rejeição entre os pares. Em H. J. Guilhardi, M. B. B. P. Madi, P. P. Queiroz \& M. C. Scoz (Orgs.), Sobre comportamento e cognição. Expondo a variabilidade (pp. 13-19). Santo André, SP: ESETec

Gomes, M. J. C. \& Scrochio, E. F. (2001). Terapia da gagueira em grupo: Experiência a partir de um grupo de apoio ao gago. Revista Brasileira de Terapia Comportamental e Cognitiva, 3, 25-34.

Gomide, P. I. C.(2003). Estilos parentais e comportamento anti-social. Em A. Del Prette \& Z. A. P. Del Prette (Orgs.), Habilidades sociais, desenvolvimento e aprendiragem: Questões conceituais, avaliação e intervenção (pp. 21-60). Campinas, SP: Alínea.

Gorayeb, R., Cunha Netto, J. R. \& Bugliani, M. A. P. (2003). Promoção de saúde na adolescência: Experiência com programas de ensino de habilidades de vida. Em Z. A. Trindade \& A. N. Andrade (Orgs.), Psicologia e saúde: Um campo em construção (pp. 89-100). São Paulo: Casa do Psicólogo.

Grossi, R. (2003). Programa de atendimento à família especial brasileira com base na análise do comportamento. Em M. Z. S. Brandão, F. C. S. Conte, F. S. Brandão, Y. K. Ingberman, C. B. Moura, V. M. Silva \& S. M. Oliane (Orgs.), Sobre comportamento e cognição. A história e os avanços, a seleção por conseqüencias em ação (pp. 455-475). Santo André, SP: ESETec.

Haase, V. G., Käppler, C. \& Schaefer, S. A. (2000). Um modelo de intervenção psicoeducacional para prevenção da violência do ambiente familiar e escolar. Em V. G. Haase, R. Rothe-Neves, C. Käppler, M. L. M. Teodoro \& G. M. O. Wood (Orgs.), Psicologia do desenvolvimento: Contribuiçoes interdisciplinares (pp. 265-282). Belo Horizonte: Health

Hermolin, M. K., Rangé, B. P. \& Porto, P. R. (2000). Uma proposta de tratamento em grupo para a depressão. Revista Brasileira de Terapia Comportamentale Cognitiva, 2, 171-179.

Jeffery, R. W. (1989). Risk behaviors and health. Contrasting individual and population perspectives. American Psychologist, 44, 1194-1202.

Lemos, M. S. \& Meneses, H. I. (2002). A avaliação da competência social: Versão portuguesa da forma para professores do SSRS. Psicologia: Teoria e Pesquisa, 18, 267-274.

Lipp, M. E. N. (1996). A eficácia do treino do controle do stress: Estudos experimentais clínicos. Em M. E. N. Lipp (Org), Pesquisas sobre stress no Brasil: Saúde, ocupações e grupos de risco (pp. 149-166). Campinas, SP: Papirus.

Löhr, S. S. (2003). Estimulando o desenvolvimento de habilidades sociais em idade escolar. Em A. Del Prette \& Z. A. P. Del Prette (Orgs.), Habilidades sociais, desenvolvimento e aprendizagem: Questões conceituais, avaliação e intervenção (pp. 293310). Campinas, SP: Alínea.

Lubi, A. P. L. (2003). Estilo parental e comportamento socialmente habilidoso da criança com pares. Em M. Z. S. Brandão, F. C. S. Conte, F. S. Brandão, Y. K. Ingberman, C. B. Moura, V. M. Silva \& S. M. Oliane (Orgs.), Sobre comportamento e cognição. A bistória e os avanços, a seleção por consequiências em ação (pp. 536-541). Santo André, SP: ESETec.

Magalhães, P. P. \& Murta, S. G. (2003). Treinamento de habilidades sociais em estudantes de psicologia: um estudo pré-experimental. Temas em Psicologia da SBP, 11. (Versão online acessada 01/10/2005)

Marinho, M. L. (2003). Comportamento anti-social infantil: Questões teóricas e de pesquisa. Em A. Del Prette e Z. A. P. Del Prette (Orgs.), Habilidades sociais, desenvolvimento e aprendizagem: Questöes conceituais, avaliação e intervenção (pp. 6181). Campinas, SP: Alínea.

Markway, B. G., Carmin, C. N., Pollard, C. A. \& Flynn, T. (1999). Morrendo de vergonha: Um guia para tímidos e ansiosos (S. Augusto, Trad.). São Paulo: Summus (Original publicado em 1992)
Marlatt, G. A. (1993). Prevenção da recaída: Estratégia e manutenção no tratamento de comportamentos adictivos (D. Batista, Trad.). Porto Alegre: ArtMed. (Original publicado em 1985)

Molina, R. C. \& Del Prette, Z. A. P. (2002). Habilidades sociais e dificuldades de aprendizagem: Uma análise funcional. [Anais] $V$ Congresso de Pesquisa e Educação da Região Sudeste: Tendências e Desafios (CDD 370), ISBN 85-903167-1-8, Aguas de Lindóia, SP.

Murta, S. G. (1999). Avaliação e manejo da dor crônica. Em M. M. M. J. Carvalho (Org.), Dor: Um estudo multidisciplinar (pp. 174-195). São Paulo: Summus.

Murta, S. G. (2005). Planejamento, implementação e avaliação de um programa de manejo de estresse ocupacional. Tese de Doutorado não-publicada, Universidade de Brasília. Brasília, DF.

Oliveira, E. A., Marin, A. H., Pires, F. B., Frizzo, G. B., Ravanello, T. \& Rossatto, C. (2002). Estilos parentais autoritário e democrático-recíproco intergeracionais, conflito conjugal e comportamentos de externalização e internalização. Psicologia: Reflexão e Crítica, 15, 1-11.

Pacheco, J. T. B., Teixeira, M. A. P. \& Gomes, W. B. (1999). Estilos parentais e desenvolvimento de habilidades sociais na adolescência. Psicologia: Teoria e Pesquisa, 15, 117-125.

Paula, J. A. (1999). Habilidades sociais em alunos de classe especial para deficientes mentais leves: análise de indicadorespré-pós intervenção. Dissertação de Mestrado não-publicada, Universidade Federal de São Carlos. São Carlos, SP.

Posavac, E. J. \& Carey, R. G. (2003). Program Evaluation. Methods and Case Studies (6 $6^{\text {th }}$ ed.). New Jersey: Prentice Hall.

Rangé, B. (2001). Programa de treinamento à distância para tratamento de transtorno do pânico e agorafobia. Em M. L. Marinho \& V. E. Caballo (Org.), Psicologia clínica e da saúde (pp. 153-175). Granada (Espanha), Londrina (Brasil): Ed. UEL e APICSA

Sarriera, J. C., Câmara, S. G. \& Berlim, C. S. (2000). Elaboração, desenvolvimento e avaliação de um programa de inserção ocupacional para jovens desempregados. Psicologia: Reflexão e Crítica, 13, 189-198.

Silvares, E. F. M. (2000). Terapia comportamental com familias de crianças agressivas: Porque, como e quando. Paidéá: Cadernos de Psicologia e Educação, 20, 24-32.

Silvares, E. F. M. (2001). Ludoterapia cognitivo-comportamental com crianças agressivas. Em H. J. Guilhardi, M. B. B. P. Madi, P. P. Queiroz \& M. C. Scoz (Orgs.), Sobre comportamento e cognição. Expondo a variabilidade (pp. 189-198). Santo André, SP: ESETec.

Silveira, J. M., Silvares, E. F. M. \& Marton, S. A. (2003). Programas preventivos de comportamentos anti-sociais: Dificuldades na pesquisa e implementação. Estudos de Psicologia (Campinas), 20, 59-67.

Vila, E. M., Silveira, J. M. \& Gongora, M. A. N. (2003). Ensinando repertório alternativo para clientes que apresentam padrões comportamentais passivo e hostil. Em C. G. Almeida (Org.), Intervenç̃és em grupo: Estratégias psicológicas para a melhoria da qualidade de vida (pp. 59-81). Campinas, SP: Papirus. 